\title{
Perancangan Prototype Smart Home Dengan Konsep Internet Of Thing ( IoT) Berbasis Web Server
}

\author{
Hasri Awal \\ Universitas Putra Indonesia "YPTK" Padang \\ Email : hasriawal.ha@gmail.com
}

\begin{abstract}
Abstrak
Seiring dengan perkembangan zaman dan meningkatnya ekonomi masyarakat permintaan akan kebutuhan rumah yang aman dan nyaman kian meningkat, serta penggunaan internet yang tanpa kita sadari hadir pada kehidupan kita sehari hari menjadikan kita sebagai masyarakat yang berada dalam putaran IoE (Internet of Everything) sehingga saya tertarik untuk mengembangkan smart home dengan konsep Internet of Thing sebagai sekala yang lebih kecil dari Internet of Everything Laporan ini adalah hasil dari pembuatan karya prototype smart home dengan konsep internet of thing menggunakan arduino Wemos D1 dan web browser, membahas mengenai cara kerja dari hubungan arduino wemos d1 yang di kontrol melalui website sebagai langkah penerapan internet of thing dengan menggunakan ip public, menggunakan device komputer sebagai perantara dan dibantu dengan.

Dengan adanya prototype ini diharapkan para pengembang selanjutnya baik dari akademisi maupun non-akademisi dapat mengetahui dan mempelajari konsep gabungan antara smart home dan internet of thing secara lebih interaktif, walaupun penulis menyadari masih banyak yang harus diperbaiki dan dikembangkan dari prototype yang penulis buat ini.
\end{abstract}

Kata Kunci : Smart Home, Internet of Thing, Prototype, Arduino Mega 2560, Wemos D1.

\section{Pendahuluan}

Di dalam sebuah penelitian yang di lakukan oleh (Adhitya Bhawiyuga, dkk, 2016) Internet of Things (IoT) adalah sebuah konsep dimana suatu objek mati memiliki kemampuan untuk menerima dan mengirimkan sebuah data melalui koneksi jaringan. Salah satu contoh IoT adalah interaksi manusia dengan sebuah perangkat, dimana perangkat tersebut digunakan untuk mengontrol sebuah lingkungan atau memonitoring kondisi sebuah lingkungan. Selain membutuhkan perangkat seperti sensor dan aktuator, untuk mengimplementasikan konsep IoT dibutuhkan peran serta teknologi lain, seperti teknologi komputer dan teknologi jaringan untuk mencapai tujuan yang di inginkan.

Perkembangan teknologi yang sangat pesat berdampak pada bertambah banyaknya protokol jaringan khususnya protokol jaringan untuk komunikasi client dengan suatu perangkat. Munculnya berbagai jenis protokol tersebut menimbulkan satu masalah yaitu membuat pengembangan sistem menjadi rumit. Untuk mengatasi masalah tersebut dibutuhkan protokol jaringan yang sederhana dan sering digunakan kebanyakan orang.

Hyper Text Transfer Protocol (HTTP) adalah salah satu protokol yang paling banyak digunakan dalam internet, dengan HTTP yang bekerja di layer TCP membuat HTTP menjadi protokol yang mampu mengirim berita, video, dan melayani banyak aplikasi web (Megyesi, Kramer \& Molnar, 1997). 
Selain membutuhkan teknologi jaringan, agar perangkat seperti aktuator atau sensor dapat bekerja maka dibutuhkan sebuah teknologi komputer berupa mikrokontroler yang berfungsi sebagai pengolah data baik itu data yang akan dikirimkan ke perangkat atau data yang diterima dari perangkat. Dalam penelitian Experiences on Using Arduino for Laboratory Experiments of Automatic Control and Robotics (Candelas, dkk, 2015). Dilakukan analisis tentang mikrokontroler Arduino dimana disimpulkan Arduino adalah sebuah mikrokontroler yang mudah dipelajari, memiliki harga yang murah serta memiliki free software. Maka dari itu, selain menggunakan protokol Web penulis juga menggunakan Arduino sebagai Mikrokontroler yang dapat membangun konsep rumah pintar ini.

\section{Landasan Teori}

\subsection{Interet Of Thing ( IoT )}

Di dalam sebuah penelitian yang di lakukan oleh (Adhitya Bhawiyuga, dkk, 2016) Internet of Thing atau IoT adalah sebuah istilah yang dimaksudkan dalam penggunaan internet yang lebih besar, mengadopsi komputasi yang bersifat mobile dan konektivitas kemudian menggabungkanya kedalam kesehari-harian dalam kehidupan kita. IoT berkaitan dengan DoT ( Disruption of Things ) dan sebagai pengantar perubahan atau transformasi penggunaan internet dari sebelumnya Internet of People menjadi Internet of M2M (Maching-to-Machine). Sedangkan C-IoT adalah singkatan dari Collaborative Internet Of Thing adalah sebuah hubungan dari dua point solusi menjadi tiga point secara cerdas, sebagai contohnya adalah iWatch salah satu smartwatch tidak hanya memanage kesehatan dan kebugaran tetapi juga dapat menyesuaikan suhu ruangan pada AC mobil. Pada model C-IoT dalam bentuk sederhanya terdiri dari Sensing, Gateway, dan Services. Pengindraan (Sensing) akan memasukan apa yang di anggap penting, Gateway akan menambah kecerdasan dan konektifitas untuk tindakan yang akan di ambil baik tingkatan lokal atau menyampaikan informasinya ke Cloud level, sedangkan Services akan menangkap informasi dan mercerna, menganalisa, dan mengembangkan wawasan untuk membantu meningkatan kualitas hidup atau improve business operation.

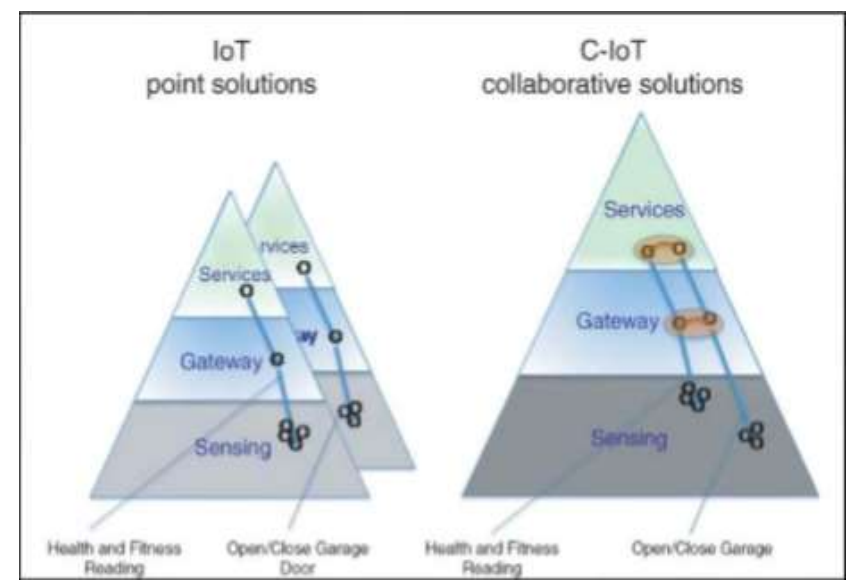

Gambar 2.1 Perbedaan IoT Dan C-IoT 


\subsection{Smarthome}

Menurut Fawzi Behmann dan Kwok Wu : Smart home adalah sebuah konsep rumah cerdas yang memanfaatkan teknologi secara maksimal, dengan kontrol terpusat untuk mengendalikan dua atau lebih sistem individu yang bertujuan meningkatkan efesiensi , kenyamanan dan keamanan.

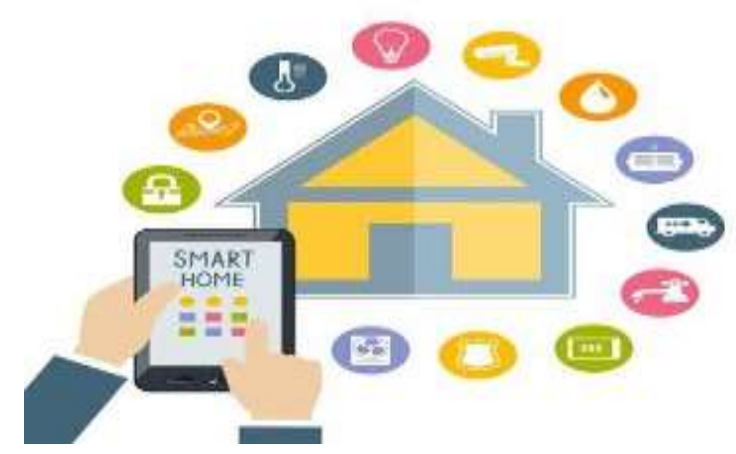

Gambar 2.2 Ilustrasi Smart Home

beberapa contoh penerapan smart home yang di bagi 4 kategori :

a) Kontrol Lingkungan

Penerapan konsep smart home pada area lingkungan rumah seperti pada taman dan pekarangan. memberikan beberapa informasi seperti suhu, kelembapan udara, dektektor banjir , tirai elektrik, dan sebagainya.

b) Efesiensi Energy

Penerapan konsep smart home untuk mengefesiensi sumber energi seperti listrik, air , gas, lemari es, kompor, pencuci piring, mesin cuci, dan sebagainya. Baik secara otomatis atau remote.

c) Keamanan dan Keselamatan ( Indor / Outdoor )

Penerapan konsep smat home untuk keamana dan keseleamatan seperti

detektor gerak, kunci pintu, jendela , garasi,dll. Baik secara otomatis atau remote.

d) Kesehatan dan Kebugaran

Penerapan konsep smart home untuk kesehatan dan kebugaran seperti iWatch yang dapat menyesuaikan suhu ruangan berdasarkan suhu badan, mencegahpenyakit kronis dengan memberikan sebuah informasi kesehatan, dan sebagainya.

\subsection{Jaringan Internet}

Menurut I Putu Agus Eka Pratama : 2014, Internet atau Internetworking secara umum didefeniskan sebagai jaringan komputer terbesar di dunia yang menghubungkan semua jaringan komputer yang ada (Intranet, Wide Area Ntework, Metroplitan Area Network, Personal area network dll ). Beserta dengan semua komputer, perangkat terhubung ( smartphone, tablet, komputer, switch, Router, Hub, dan perangkat penghubung lainnya), serta pengguna komputer itu sendiri, ke dalam suatu wadah jaringan komputer dunia. Gambar berikut mengilustrasikan keterkaitan anatara Internet LAN, MAN, dan WAN, sebagaimana yang telah di jelaskan diatas : 


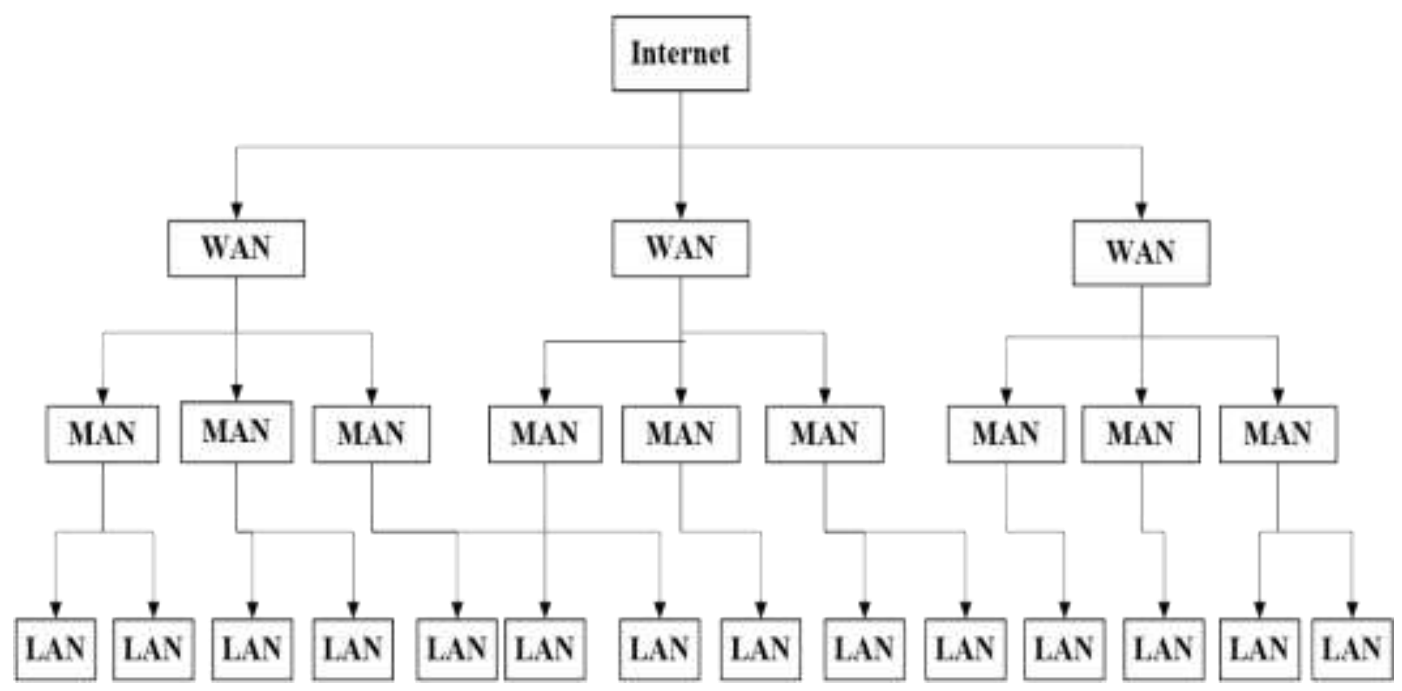

Gambar 2.3 Keterkaitan Internet LAN, MAN dan WAN

Penjelasan dari bagan di atas adalah, dimana jaringan internet sebagai pusat inti dari sebuah jaringan yang menghubungkan antara beberapa jenis jaringan lokal yang semua nya saling terkait antara yang satu denganyang lainnya.

\subsection{Webiste}

Website adalah halaman informasi yang disediakan melalui jaringan internet sehingga bisa di akses diseluruh dunia Selama masih tetkoneksi dengan intrenet. Website merupakan kompnen atau kumpulan komponen yang terdiri dari teks, gambar, suara animasi, sehingga lebih merupakan media informasi yang menarik untuk dikunjungi. Webiste bisa digolongkan ke menjadi 3 bagian :

1. Website Statis

Adalah web yang mempunyai halaman tidak berubah, artinya adalah untuk melakukakan sebuah perubahan pada suatu halaman web dilakukan secar manual dengan mengedit kode yang menjadi struktur dari website tersebut.

2. Website dinamis

Merupakan website yang secara struktur digunakan untuk udate terus - menerus. Biasnya selain utama yang bisa diakses oleh user pada umumnya, juga disediakan halaman backand untuk mengedit kontent dari website.

3. Website interaktif

Adalah webiste yang saat ini memang sedang populer. Salah satu contoh website interaktif adalah blog dan Forum. Di website ini user bisa berinteraksi dan bersaing pendapat mengenai apa yang menjadi pemikiran.

\subsection{Pemograman}

\subsubsection{PHP}

Menurut buku yang di tulis Oleh "I Komang Setia Buana" PHP merupakan aplikasi perangkat lunak opensorce, dimana kepanjangan PHP adalah Hypertext Preprocessor yag diatur dalam aturan general purpose license (GPL), Pemograman PHP 
merupakan pemograman yang sangat cocok dikembangkan di lingkungan web karena bisa diletakkan pada script HTML ataupun sebalikya. PHP tergolong tergolong sebagai pemograman web dinamis karena mampu menghasilkan webiste yang bisa diubah secara terus menerus hasilnya atau kontenya tanpa harus masuk ke dalam kodding. Hal tersebut bergantung kepada permintaan terkini. Secara umum, pembuatan database sangat erat hubungannya untuk pembuatan web dinamis, senagai tempat untuk sumber data yan akan ditampilkan.

PHP juga merupakan bahasa pemograman berbasis server. Ini berarti setiap pemogramam PHP harus diletakkan di server terlebih dahulu, kemudian di terjemahkan oleh web server dan hasilnya akan dikirimkan kan ke web client. Kemampuan dan fitur PHP yang paling mendukung banyak basis sata yaitu MSSQL, MYSQL, Oracle, dan Postgre SQL. Berikut adalah contoh dari Script PHP :

$<$ ?php \$nama = "Fadel Muhammad";

$\$$ umur = 22;

echo "Hai nama saya “.\$nama." $<$ br $/>$ ";

echo "Umur saya saat ini ". \$umur;

?>

Penulisan script PHP selalu di awali dengan <?php dan ?> sebagai penutup script. Salah satu kelebihan PHP adalah dapat berjalan di berbagai macam sistem opreasi seperti Linux, Windows, atau Mac. Extention untuk file PHP pada umunya adalah “.php”.

\subsubsection{HTML}

Menurut buku yang di tulis oleh "Priyanto Hidayatulah" adalah suatu metode untuk mengimplementasikan konssep Hypertext dalam suatu naskah atau dokumen. HTML sendiri bukan tergolong pada suatu bahasa pemograman karna sifatnya yang memberikan tanda ( marking up ) pada suatu naskah dan buku sebagai program.

Pengertian HTML bila dijabarkan berdasarkan kata kata penyusunannya HTML dapat diartikan lebih dalam lagi menjadi :

1. Hypertext

Link Hypertext adalah kata atau frasa yang dapat menujukkan hubungan suatu naskah dokumen dengan naskah naskah lainya. Jika kita klik pada kata atau frasa untuk mengikuti link ini maka web browser akan memindahkan tampilan pada bagian lain dari naskah atau dokumen yang kita tuju.

2. Markup

Pada pengertiannya disini markup menunjukkan bahwa pada file HTML berisi suatu instruksi tertentu yang dapat memberikan suatu format pada dokumen yang akan ditampilkan di pada World Wide Web ( WWW ).

3. Language

Meski HTML sendiri bukan merupakan bahasa pemograman, HTML merupakan kumpulan dari beberapa instruksi yang dapat digunakan untuk mengubah- ubah format suatu naskah atau dokumen.

Pada awalnya HTML dikembangkan sebagai subsket STML ( standart General markup Leanguage ). Karna HTML didedikasikan untuk ditampilkan melalui internet maka HTML relatif lebih sederhana daripada SGML yang lebih ditekankan pada format dokumen yang berorientasi pada aplikasi. Contoh script HTML : 


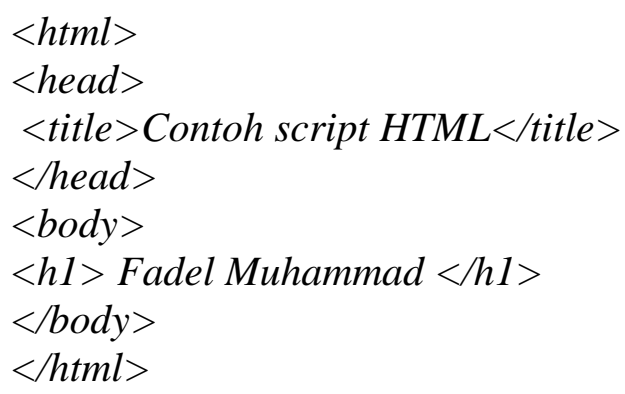

\subsection{Arduino Mega 2560}

Arduino Mega 2560 adalah sebuah papan mikrokontroler berbasis Atmega 2560 (datasheet). Mempunyai 54 pin digital input/output (dimana 14 pun dapat diguanakan sebagai keluaran PWM), 16 pin input analog, 2 UARTs (Hardware serial ports), sebuah crystal oscillator $16 \mathrm{MHz}$, sebuah penghubung USB, sebuah colokan listrik, ICSP header, dan tombol kembali. Setiap isi dari Arduino Mega 2560 membutuhkan dukungan mikrokontroler; koneksi mudah antara Arduino mega 2560 ke komputer dengan sebuah kabel USB atau daya dengan AC to DC adaptor atau baterai untuk memulai. Arduino mega cocok sebagai rancangan pelindung untuk Arduino Deumilanove atau Diecimila.

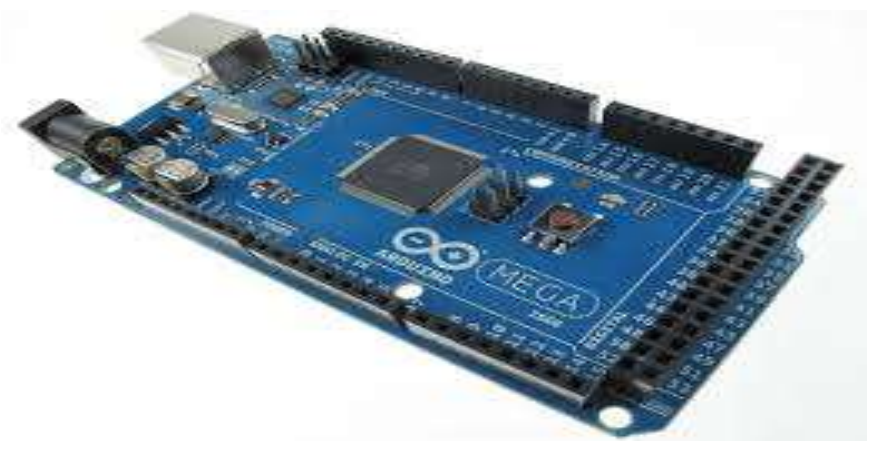

Gambar 2.5 Arduino Mega 2560

\subsection{Wemos D1}

WeMos D1 mini adalah modul development board WiFi ESP8266 yang dapat diprogram via Arduino IDE atau NodeMCU. Wemos D1 mini ini sendiri secara kinerja tentunya lebih baik daripada arduino dikarenakan speed dari controller yang lebih tinggi ditambah telah terintegrasi dengan WIFI sehingga memungkinkan updating Sofwtare via OTA (Over The Air). Gambar 2.6 berikut bentuk fisik dari Wemos D1.

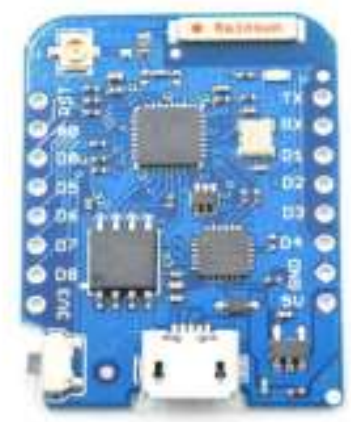

Gambar 2.6 Wemos D1 
Pada Microcontroller wemos memiliki 2 buah chipset yang digunakan sebagai otak kerja platform tersebut. Beberapa chipset pada Microcontroller ini adalah :

\section{a. Chipset ESP8266}

ESP8266 adalah sebuah chip microcontroller yang memiliki fitur Wi-Fi yang mendukung stack TCP/ IP.Diproduksi oleh produsen Cina yang berbasis di Shanghai, Espressif. Pada Agustus 2014 AI-Thinker membuat modul ESP-01 dengan menggunakan lisensi oleh Espressif. modul kecil ini memungkinkan microcontroller untuk terhubung dengan jaringan Wi-Fi dan membuat koneksi TCP / IP hanya dengan menggunakan command yang sederhana seperti Hayes-gaya. Harga yang sangat rendah dan sangat sedikit komponen eksternal pada modul ini mengakibatkan sangat murahnya harga sebuah chip ini. Dengan clock $80 \mathrm{MHz}$ chip ini dibekali dengan 4MB Eksternal RAM, mendukung format IEEE $802.11 \mathrm{~b} / \mathrm{g} / \mathrm{n}$ sehingga tidak menyebabkan interference bagi yang lain. Mendukung enkripsi WEP, WPA sehingga menjadikan chipset ini sangat aman digunakan. Chipset ini memiliki 16 GPIO pin yang berkerja pada 3.3 Volt, 1 pin ADC dengan resolusi 10 bit.

\section{b. ChipsetCH340}

CH340 adalah sebuah Chipset yang mengubah USB menjadiserialinterface. Sebagai contohnya adalah aplikasi USB converter to IrDA atau aplikasi USB converter to Printer.Dalam modeserial interface $\mathrm{CH} 340$ mengirimkan sinyal penghubung yang umum digunakan pada MODEM.CH340 digunakan untuk memperbesar Asynchronous serial interface komputer atau mengubah perangkat serial interface umum untuk berhubungan dengan bus USB secara langsung.

\section{Desain Dan Pembuatan Sistem}

\subsection{Context Diagram}

Sub bab ini merupakan penjabaran setiap external entity secara keseluruhan yang digambarkan melalui context diagram. Context diagram merupakan pendefinisian terhadap sistem yang akan dirancang yang bersifat menyeluruh. Context diagram ini digunakan untuk memudahkan dalam proses penganalisaan sistem yang dirancang secara keseluruhan. Context diagram berfungsi sebagai media, yang terdiri dari suatu proses dan beberapa external entity. Context diagram yang dimaksud dapatdiliha pada gambar 3.1 berikut ini.

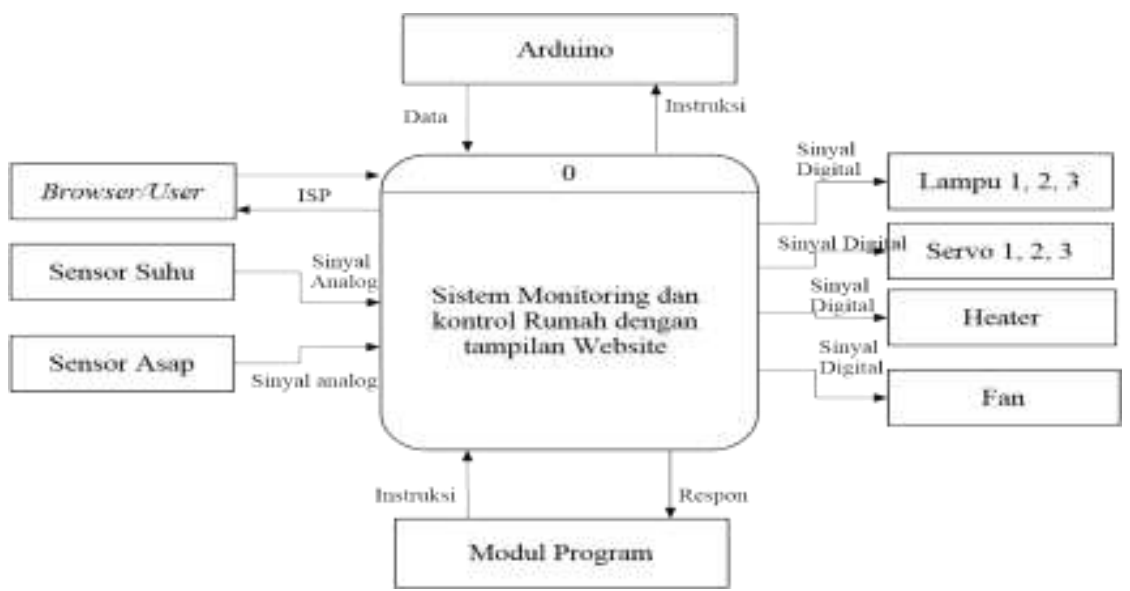

Gambar 3.1 Context Diagram 


\subsection{Data Flow Diagram}

Data flow diagram adalah gambaran yang lebih rinci dari alat yang dirancang. Data flow diagram diuraikan berdasarkan context diagram yang telah dijabarkan sebelumnya. Gambar data flow diagram dapat dilihat pada gambar 3.2 berikut ini :

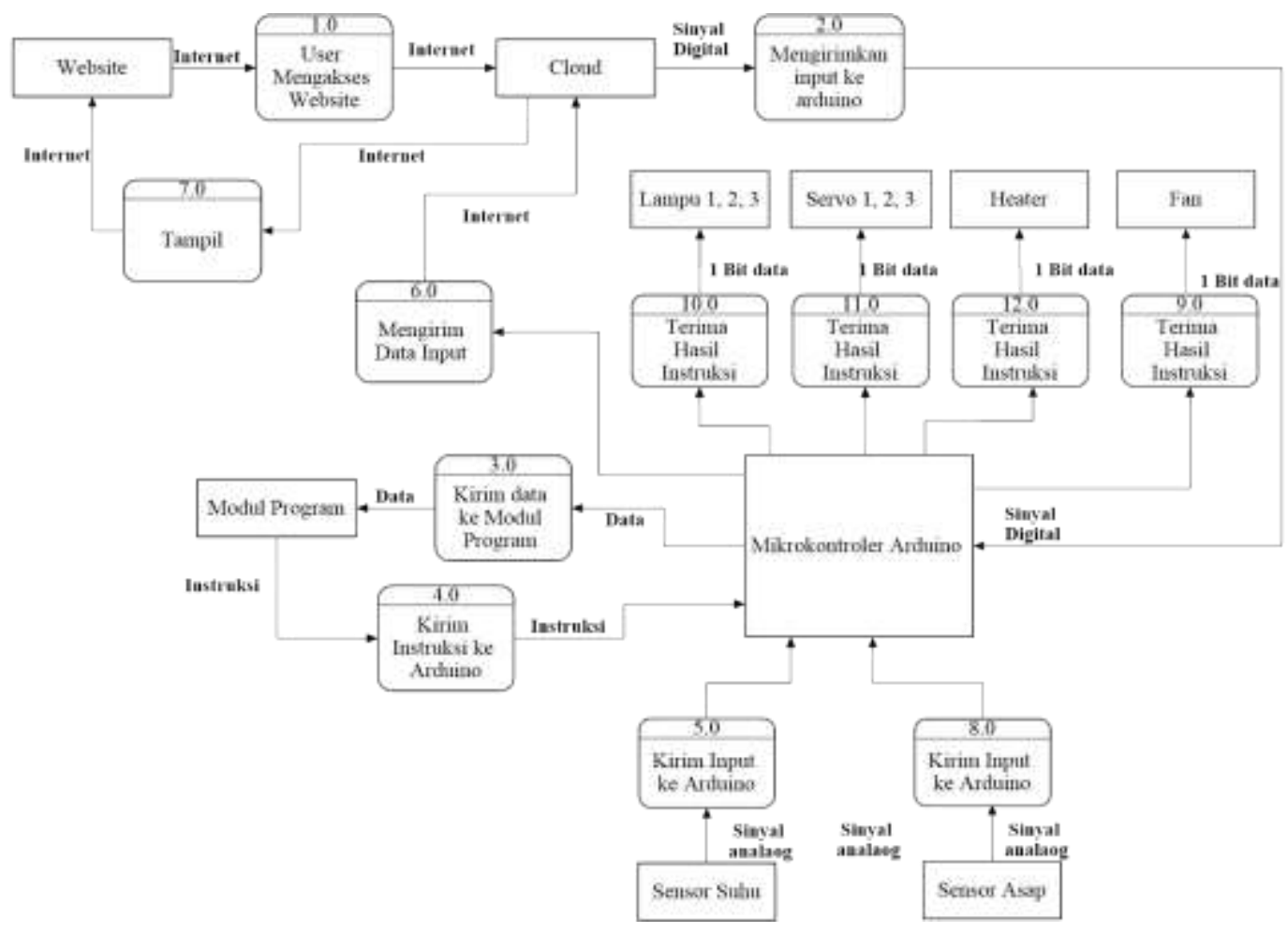

Gambar 3.2 Data Flow Diagram

\subsection{Blok Diagram}

Dari perencanaan dan perancangan peralatan yang dibuat, dapat digambarkan blok diagram sebagai berikut :

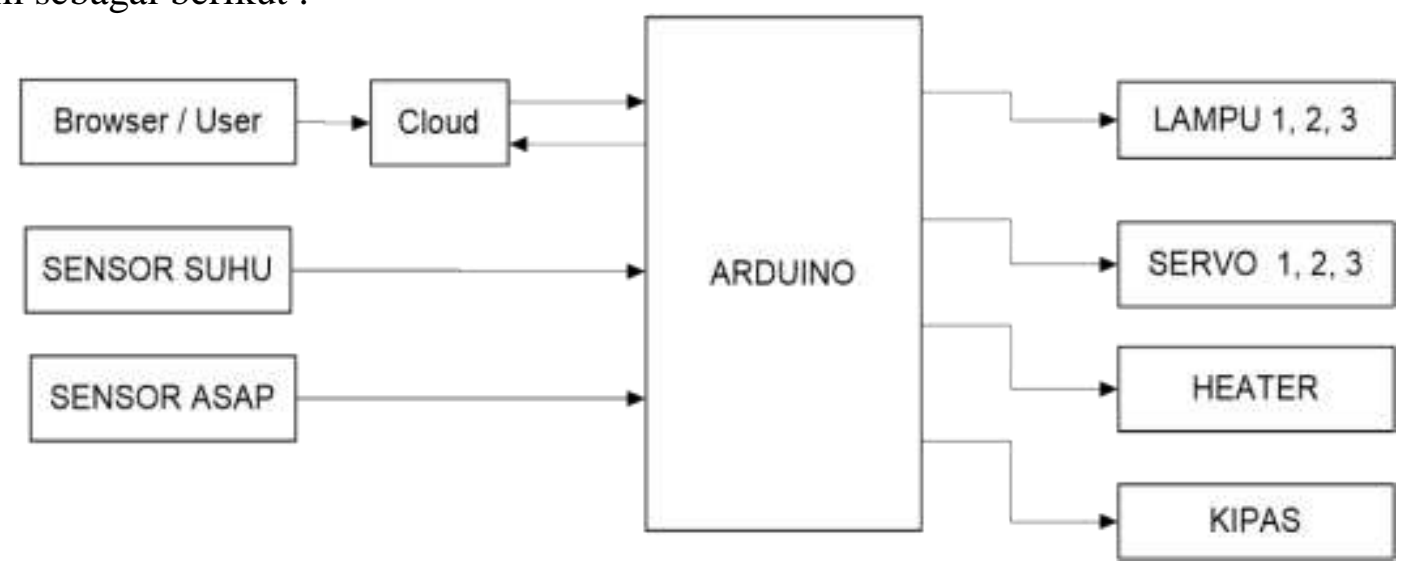

Gambar 3.3 Blok Diagram 


\subsection{Flowchart}

Modul program dirancang memiliki struktur dengan kualitas yang baik dan mudah dimengerti, maka sebelum pembuatan listing program perlu diawali dengan penentuan logika program. Logika dasar gambaran pada penulisan ini adalah dengan menggunakan flowchart seperti gambar 3.12 berikut ini :

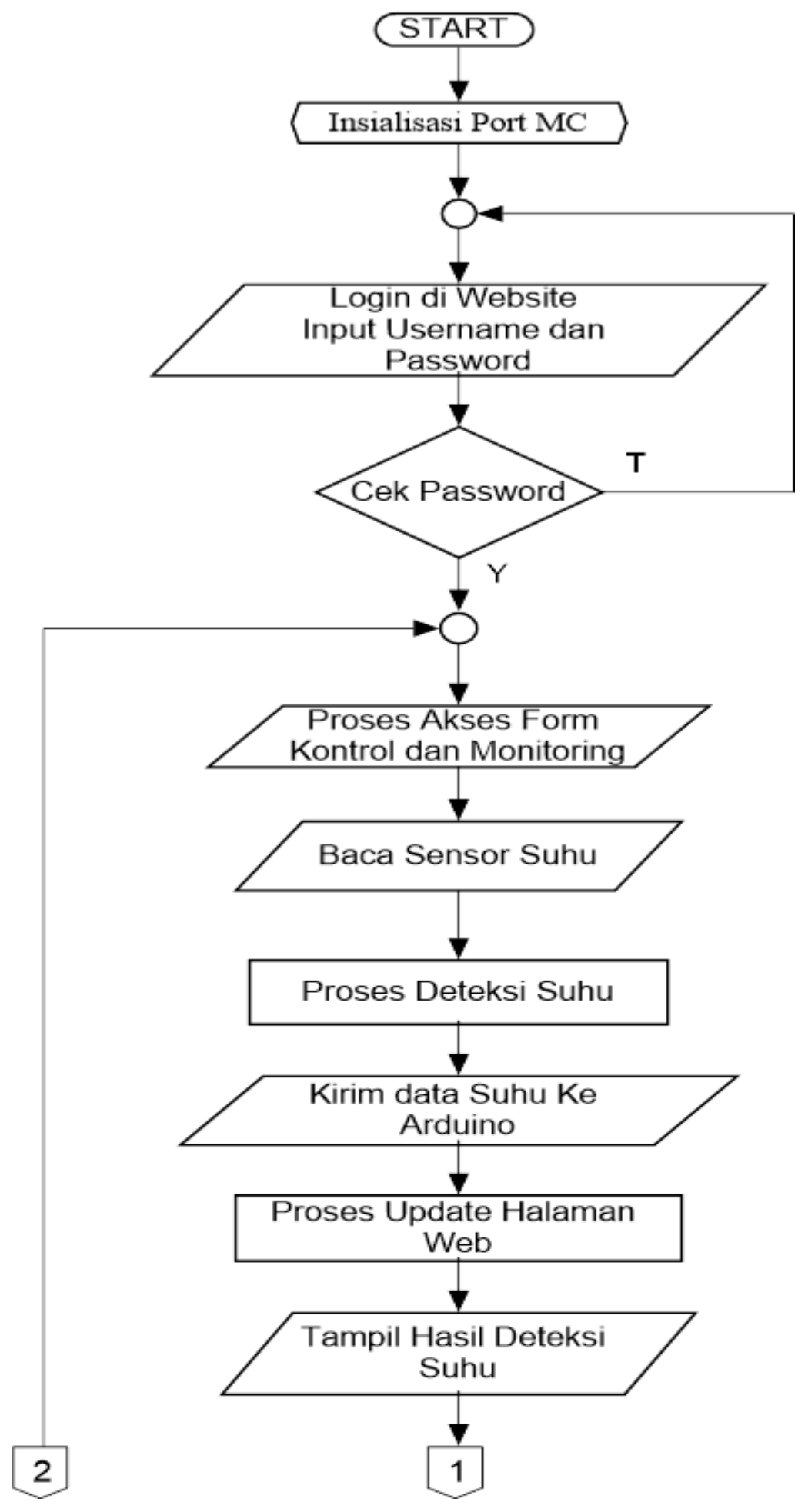




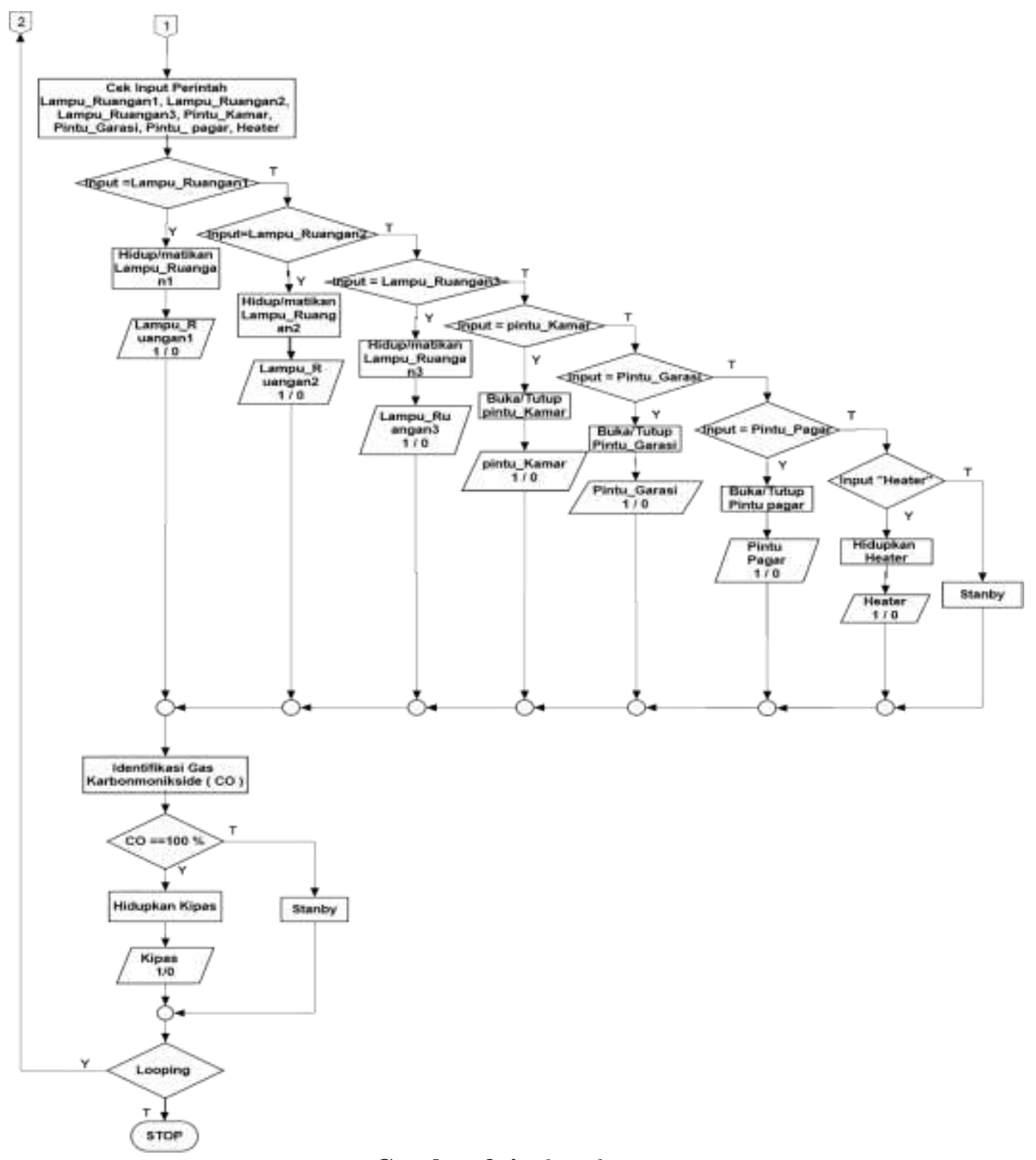

Gambar 3.4 Flowchart

\section{Implementasi dan Pengujian Sistem}

\subsection{Pengujian Sistem.}

Pengujian sistem ini dapat dilakukan mulai dari pengujian alat per modul atau rangkaian sampai pengujian alat secara keseluruhan. Langkah-langkah dalam pengujian alat tersebut adalah sebagai berikut.

\subsubsection{Pengujian Sensor Suhu}

Pengujian komponen sensor Suhu berfungsi untuk melakukan pendeteksian terhadap suhu ruangan sehingga diketahui berapa tingkat keadaan suhu suatu ruangan tersebut : 


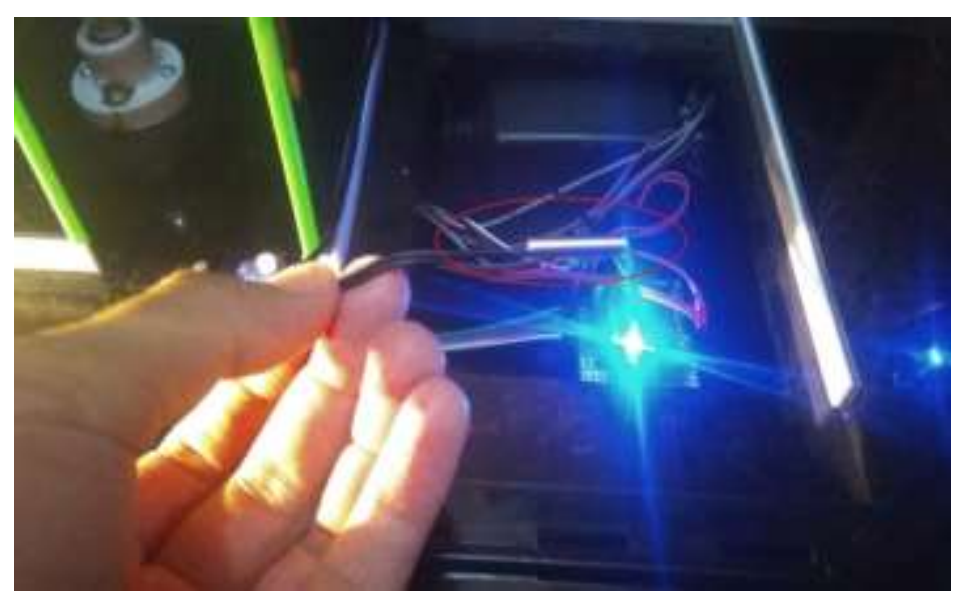

Gambar 4.1 Pengujian Sensor Suhu

\subsubsection{Pengujian Rangkaian Motor}

Rangkaian ini berfungsi untuk mengaktifkan motor Servo pembuka dan penutup pintu Rumah ataupun pagar rumah. Tegangan yang berasal dari pin data port arduino mengeluarkan tegangan 5 volt. Dan mengeluarkan arus sebesar 5volt untuk menggerakkan Motor. Seperti gambar 4.2 :

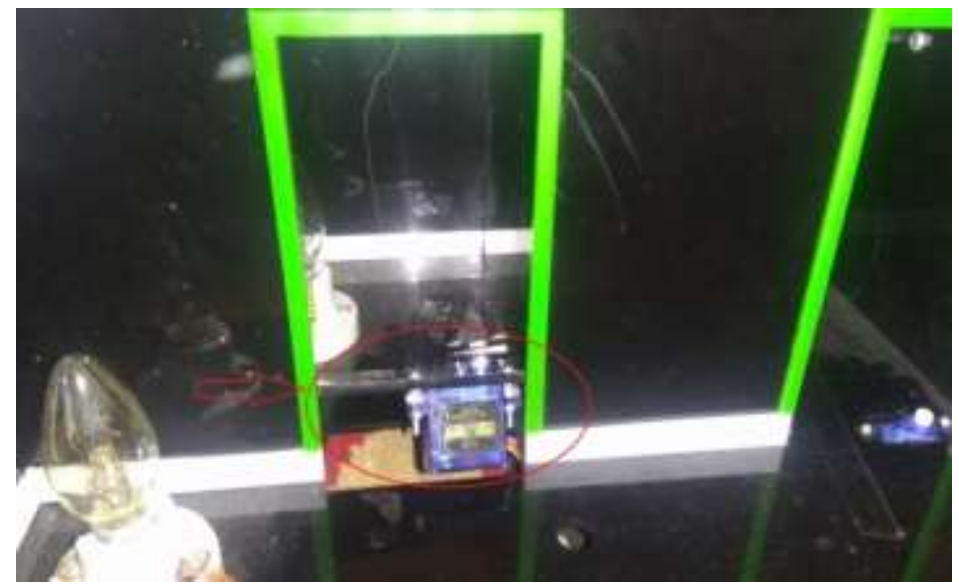

Gambar 4.2 Pengujian Rangkaian Motor Servo

\subsubsection{Pengujian Sistem Aplikasi Website}

Pengujian sistem aplikasi webiste dilakukan dengan tujuan mengetahui bagian bagian apa saja yang terdapat dan diterapkan. Pada aplikasi ini penulis menggunakan 2 buah webiste yaitu, webiste yang penulis rancang sendiri yaitu dengan alamat www.skripsifadel.web44.net dimana webiste ini digunakan untuk memberikan informasi kepada pengguna / user tentang apa itu Internet of thing, smarthome dll. Website yang kedua yaitu www.geeknesia.com yaitu sebuah webiste resmi untuk para pengembang / developper Internet of thing, dimana website ini penulis akses melaui webiste yang penulis telah rancang sebelumnya. 


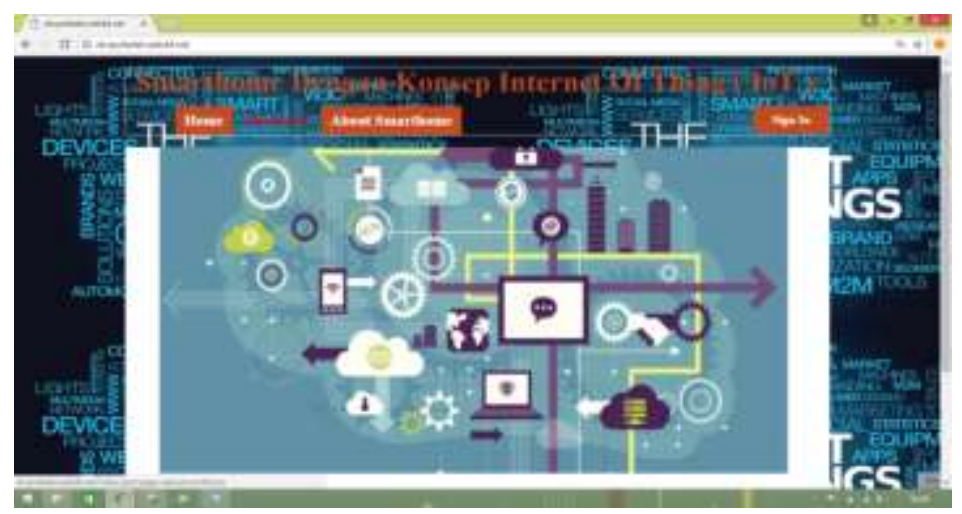

Gambar 4.3 Tampilan Halaman Utama

\subsubsection{Pengujian Sistem Keseluruhan}

Pengujian sistem aplikasi keseluruhan ini dilakukan dengan tujuan mengetahui bagaimana penggunaan sistem ini bekerja, dan proses proses apa saja yang dilakukan agar sistem dapat bekerja sesuai dengan apa yang diharapkan. Adapun langkah-langkah pengujiannya adalah sebagai berikut :

1. Buka web browser yang terdapat di samrtphone atau laptop dan masukkan $U R L$ : www.skripsifadel.web44.net lalu enter dan akan terbuka tampilan seperti pada gambar 4.4 berikut :

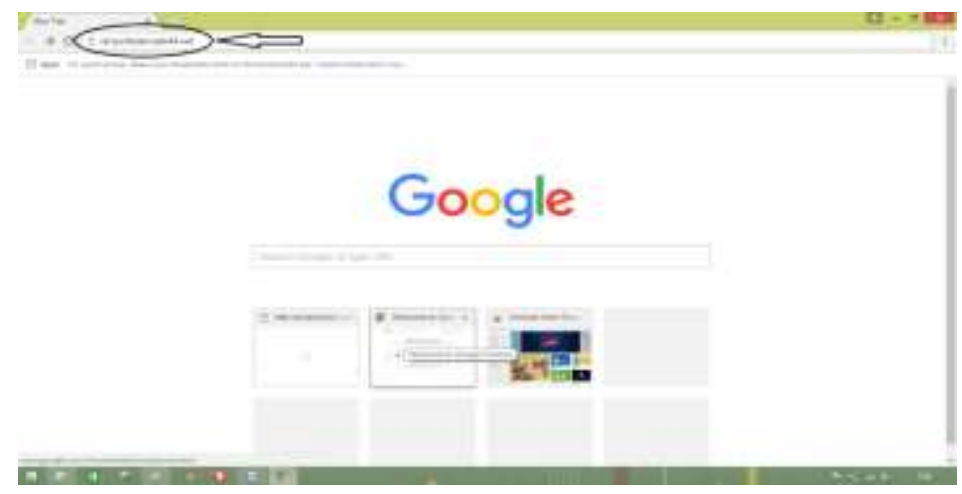

Gambar 4.4 Tampilan Akses Halaman Webiste

2. Setelah tampilan utama terbuka lalu pilih menu bar Sign In yang terdapat di pojok kanan atas webiste. Seperti yang terlihat pada gambar 4.5 berikut :

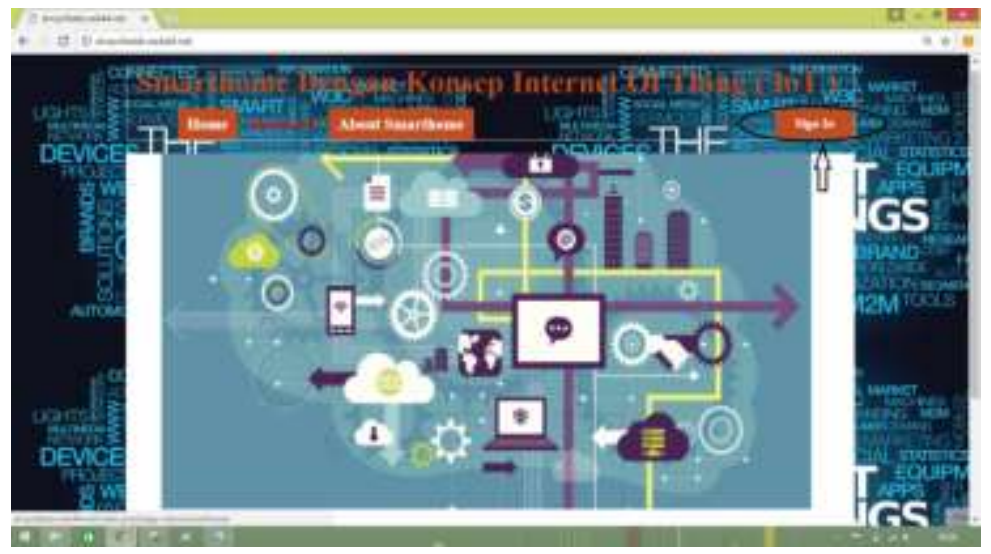

Gambar 4.5 Tampilan Menu Home dan Sign In 
3. Dan menu login akan terbuka, lalu masukkan Username dan password pada form yang telah tersedia, dan klik Login. Seperti terlihat pada gambar 4.6 berikut :

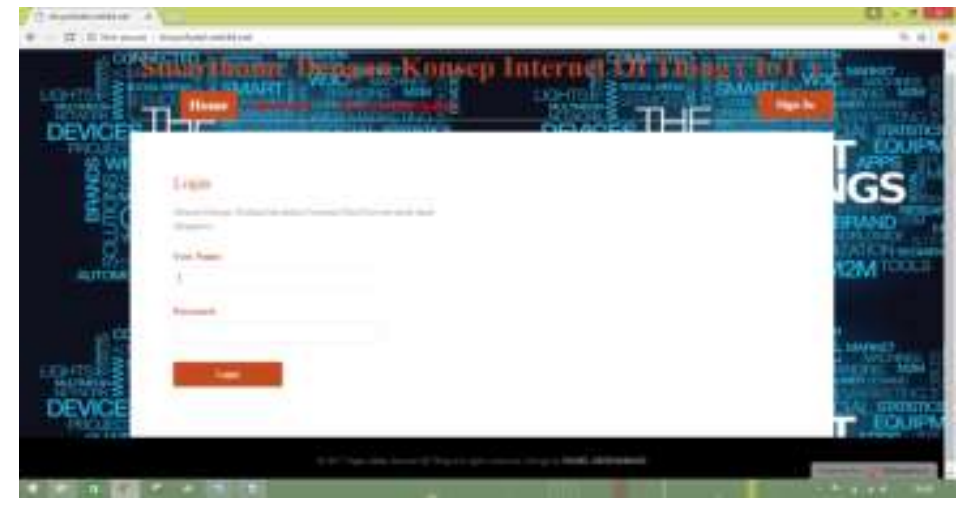

Gambar 4.6 Tampilan Input Username dan Password

4. Setelah berhasil login maka akan muncul form dimana terdapat tombol akses menuju link website ke dua untuk mengontrol dan memonitoring rumah yaitu dengan mengklik Tombol "form kontrol dan monitoring rumah " seperti pada gambar 4.7 berikut :

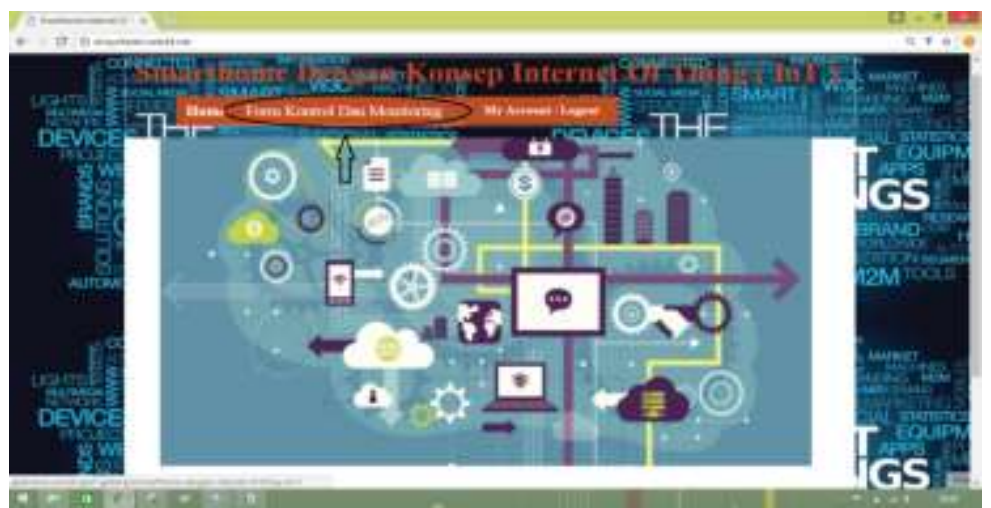

Gambar 4.7 Tampilan Menu Form Kontrol Dan Monitoring

5. Pada webiste kedua inilah seluruh aktifitas didalam rumah dapat di kontrol, seperti menghidupkan lampu, menutup pintu dll dengan mengklik $2 x$ tombol yang terdapat pada form di webiste tersebut seperti terlihat pada gambar 4.8 berikut ini

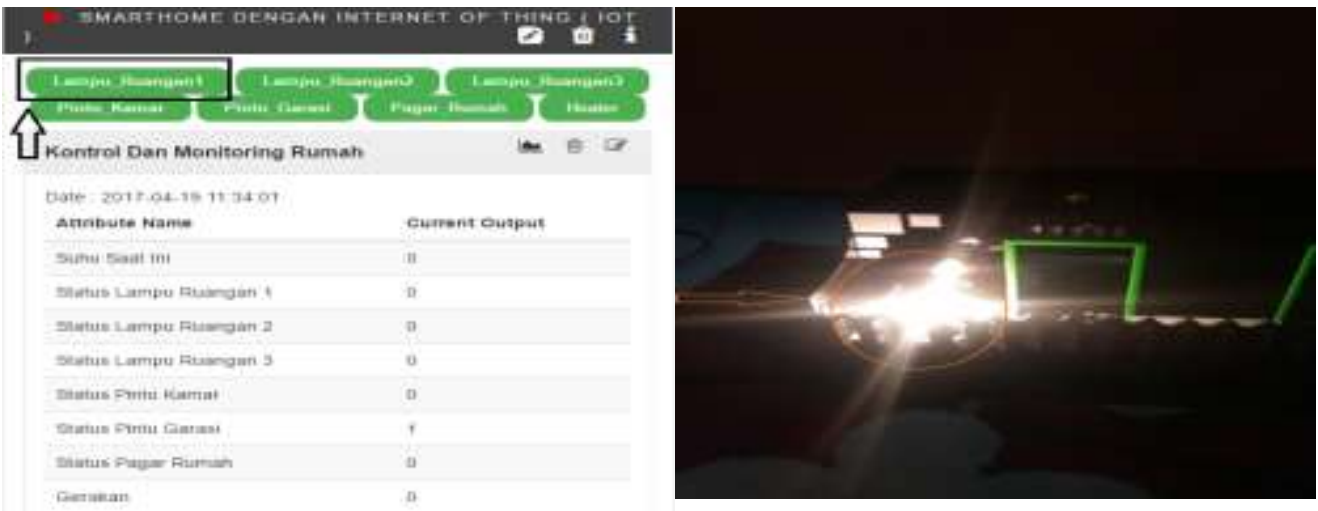

Gambar 4.8 Tampilan Tombol Lampu 1 Di Klik 
6. Selanjutnya adalah mengukur suhu ruangan yaitu menggunakan sensor suhu jenis thermocouple dapat di uji dengan memanaskan sensor dengan alat pemanas, dan hasilnya langsung dikirimkan ke webiste tanpa harus me Reload / refresh webiste terlebih dulu, dan hasil yang ditampilkan di webiste adalah berupa angka dalam satuan derjat celcius seperti terlihat pada gambar 4.9 berikut :
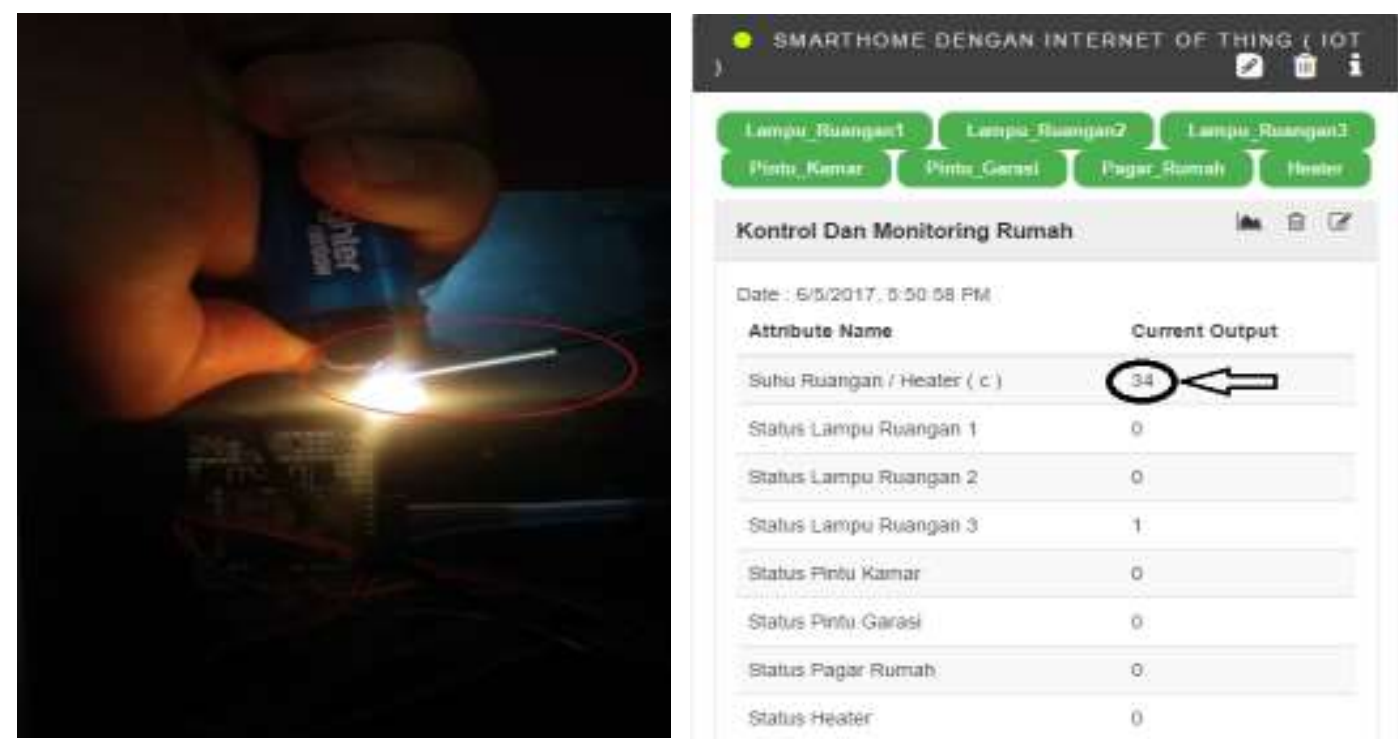

Gambar 4.9 Tampilan Mengukur Suhu Ruangan

7. Selanjutnya adalah dengan mengklik tombol Pagar_rumah di tombol webiste, akan memberikan respon ke alat seperti yang terlihat pada gambar 4.10 berikut :

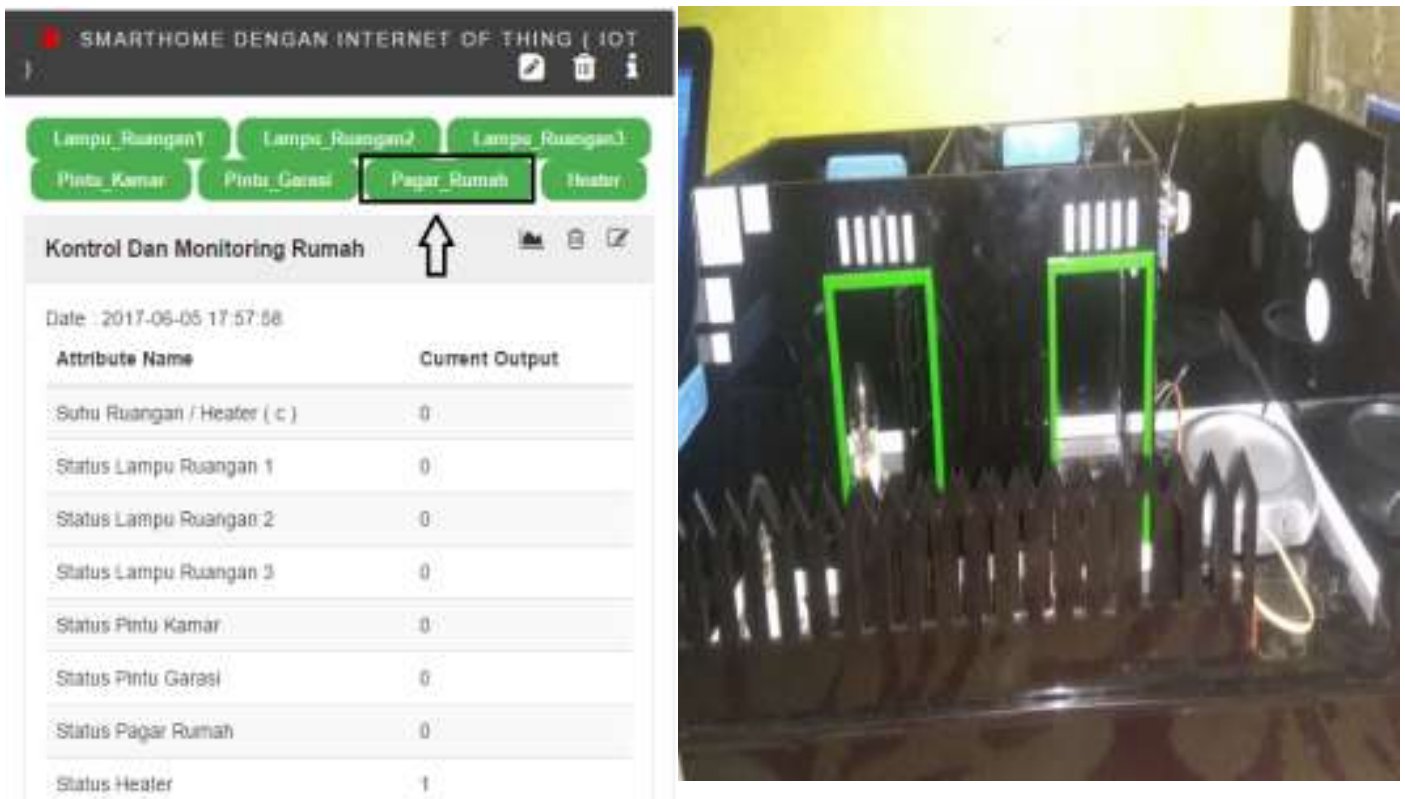

Gambar 4.10 Tampilan Pagar Terbuka / Tertutup 


\section{Kesimpulan}

Prototype Smart Home adalah sebuah Prototype untuk simulasi dari Smart Home atau rumah pintar dengan Konsep Internet Of Thing, Konsep internet of thing sebuah konsep yang memungkinkan kendali sebuah device melalui internet. Tampilan aplikasi yang penulis buat telah memenuhi standart aplikasi yang baik :

Adapun Hasil kesimpulan dari penggunaan Prorotype Smart Home dengan Konsep Internet of Thing adalah :

1. Seseorang dapat mengetahui konsep Smart Home dengan lebih interaktif melalui alat Miniatur / Maket.

2. Seseorang dapat memanfaatkan penggunaan jaringan internet untuk keperluan lain, selain untuk media sosial, juga dapat digunakan untuk mengontrol alat rumah tangga seperti : mematikan lampu, mengunci pintu, dll.

3. Memperkenalkan pemahaman tentang teknologi terbaru bagi orang yang belum mengenal teknologi, Khusus nya tentang teknologi Internet Of Thing ( IoT ).

4. Memberikan solusi awal bagi seseorang yang ingin mengembangkan konsep smart home dan internet of thing dalam Kalangan Rumah Tangga .

\section{DAFTAR PUSTAKA}

[1] Andi, Membangun sistem jaringan komputer, Yogyakarta : Andi Offset, 2011.

[2] Agus Saputra, Sistem Informasi Nilai Akademik Untuk Panduan Skripsi , Yogyakarta : Andi Offset, 2012

[3] Bhawiyuga Aditya, Dkk, Rancang Bangun Sistem Kontrol dan Monitoring Berbasis websocket Pada Perangkat Arduino, Jurnal Seminar nasional Riset Terapan, 2016.

[4] Dewi Ernita, Internet Of Things - Keamanan Dan Privasi , Jurnal Teknik Elektro 2015.

[5] Hartika Ruri, Sistem Keamanan Ruangan Menggunakan Sensor Passive Infrared ( PIR ) Dilengkapai Kontrol Penerangan pada Ruangan Berbasis Mikrokontroler Atmega 8535 , Jurnal Teknologi Informasi dan pendidikan VOL. 6 NO. 1 Maret 2013.

[6] Hidayatullah Priyanto, Pemograman Web, Bandung : Informatika Bandung, 2014.

[7] I Putu Agus Eka Pratama, Hand Book Jaringan Komputer, Bandung : Informatika Bandung, 2014.

[8] Kadir Abdul, Panduan Praktis Mempelajari Apilkasi Mikrokontroler Dan Pemrogramannya menggunakan Arduino, Yogyakarta : Andi Offset, 2013.

[9] Kadir Abdul, Pengenalan Sistem Informasi, Yogyakarta : Andi Offset, 2003.

[10] Komang I, Jago Pemograman PHP Untuk pemula dan orang awam. Jakarta Timur: Dunia Komputer, 2014.

[11] Muhammad Fathoni, pengantar Analisa perancangan system, Yogyakarta Andi Offset, 2013.

[12] Nalwan Andi, Teknik Rancang Bangun Robot, Yogyakarta: Andi Offset, 2012.

[13] Prihatmoko Dias, Penerepan Internet Of thing ( IoT ) Dalam Pembelajaran di Unisnu Jepara, Jurnal SIMETRIS, vol 7 No 2 November 2016.

[14] Pusteba Tim ITB, Jurus Kilat Jago Membuat Robotika, Bekasi: Dunia Komputer, 2011.

[15] Pasaribu dkk, Jurnal Teknologi Dan Sistem Informasi, Pemasaran Jamu Tradisional Menggunakan E-Commerse, Vol. 1, 2014.

[16] Suarga.,Algoritma Dan Pemrograman. Yograkarta: Andi Offset, 2012.

[17] Syahwill Mohammad, Panduan Mudah Simulasi dan Praktik MikrokontrolerArduino, Yogyakarta: Andi Offset, 2013.

[18] Sulindawati, Muhammad Fatoni, Pengantar analisa perancangan sistem, (2010)

[19] Widodo Budiharto, Sigit Firmansyah. Elektronika digital dan Mikroprosesor, Yogyakarta: Andi Offset, 2010 